\title{
Cordyceps sinensis inhibits airway remodeling in rats with chronic obstructive pulmonary disease
}

\author{
LEI YANG ${ }^{1,2^{*}}$, XINGAI JIAO ${ }^{1 *}$, JINXIANG WU $^{1}$, JIPING ZHAO $^{1}$, TIAN LIU ${ }^{1}$,

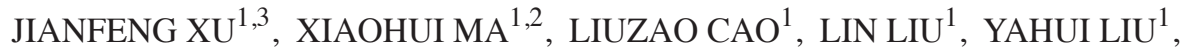 \\ JINGYU CHI ${ }^{2}$, MINFANG ZOU ${ }^{1}$, SHUO LI ${ }^{1}$, JIAWEI XU ${ }^{1}$ and LIANG DONG ${ }^{1}$ \\ ${ }^{1}$ Department of Pulmonary Medicine, Qilu Hospital of Shandong University, Jinan, Shandong 250012; \\ ${ }^{2}$ Department of Tuberculosis, Shandong Provincial Chest Hospital, Jinan, Shandong 250013; \\ ${ }^{3}$ Department of Pulmonary Medicine, Yuhuangding Hospital, Yantai, Shandong 264000, P.R. China
}

Received June 8, 2017; Accepted November 9, 2017

DOI: 10.3892/etm.2018.5777

\begin{abstract}
Cordyceps sinensis is a traditional Chinese herbal medicine that has been used for centuries in Asia as a tonic to soothe the lung for the treatment of respiratory diseases. The aim of the present study was to determine the effects of $C$. sinensis on airway remodeling in chronic obstructive pulmonary disease (COPD) and investigate the underlying molecular mechanisms. Rats with COPD were orally administered $C$. sinensis at low, moderate or high doses $(2.5,5$ or $7.5 \mathrm{~g} / \mathrm{kg} /$ day, respectively) for 12 weeks. Airway tissue histopathology, lung inflammation and airway remodeling were evaluated. $C$. sinensis treatment significantly ameliorated airway wall thickening, involving collagen deposition, airway wall fibrosis, smooth muscle hypertrophy and epithelial hyperplasia in model rats with COPD. Additionally, $C$. sinensis administration in rats with COPD reduced inflammatory cell accumulation and decreased inflammatory cytokine production, including tumor necrosis factor- $\alpha$, interleukin- 8 and transforming growth factor (TGF)- $\beta 1$ in bronchoalveolar lavage fluid. Meanwhile, the increased levels of $\alpha$-smooth muscle actin and collagen I in the COPD group were also markedly decreased by $C$. sinensis treatment. Furthermore, compared with untreated rats with COPD, $C$. sinensis reduced the expression level of phosphorylated (p)-Smad2, p-Smad3, TGF- $\beta 1$ and its receptors, with the concomitant increased expression of Smad7 in the lungs of rats with COPD. These results indicated that treatment with C. sinensis may be a useful approach for COPD therapy.
\end{abstract}

Correspondence to: Professor Liang Dong, Department of Pulmonary Medicine, Qilu Hospital of Shandong University, 107 Wenhuaxi Road, Jinan, Shandong 250012, P.R. China

E-mail:d15506@126.com

${ }^{*}$ Contributed equally

Key words: Cordyceps sinensis, chronic obstructive pulmonary disease, airway inflammation, airway remodeling, transforming growth factor- $\beta 1 /$ Smad signaling pathway

\section{Introduction}

Chronic obstructive pulmonary disease (COPD) is a common chronic inflammatory disease of the airways $(1,2)$ that is characterized by poorly reversible airflow limitation and structural changes in the airway components, known as remodeling (3). Airway remodeling is strongly associated with the progression of COPD. Current therapy for COPD predominantly focuses on the relief of respiratory symptoms and cannot alleviate the long-term deteriorating pulmonary function effectively due to airway remodeling (4). Therefore, novel therapeutic strategies and medications to prevent airway remodeling for COPD are highly demanded.

The major pathological features of airway remodeling in COPD include goblet cell hyperplasia, collagen deposition and smooth muscle hyperplasia, as well as airway wall fibrosis $(4,5)$. Previous studies have demonstrated that chronic airway inflammation was closely associated with airway remodeling and is involved in airway injury and repair in COPD (6-8). Chronic inflammation causes airway structural changes and narrowing of the small airways $(7,8)$. Transforming growth factor (TGF)- $\beta 1$, a key profibrotic mediator, serves a critical role in inflammatory injury and repair, contributing to the development of airway remodeling in COPD $(9,10)$. TGF- $\beta 1$ has been indicated to be increased in airway epithelium, airway smooth muscle, fibroblasts and macrophages in lungs of patients with $\operatorname{COPD}(11,12)$. These observations suggest that TGF- $\beta$ signaling has an impact on the development and progression of COPD. Research has indicated that the TGF- $\beta 1 /$ Smad signaling pathway notably impacts respiratory disease and induces a series of pathological reactions related to airway remodeling $(13,14)$. Following the binding of TGF- $\beta$ to its receptors, Smad 2 or Smad 3 phosphorylates and binds to Smad4, resulting in the alteration of TGF- $\beta$ target genes, including $\alpha$-smooth muscle actin (SMA) and collagen I $(13,15,16)$. This whole process is essential for the pathogenesis of COPD airway remodeling. Smad7 exerts a negative effect on TGF- $\beta /$ Smad signaling $(17,18)$; therefore, inhibiting the TGF- $\beta 1 /$ Smad signaling pathway may lead to novel therapeutic strategies against COPD.

Cordyceps sinensis has been used as a type of traditional Chinese natural drug that has been demonstrated to possess 
various therapeutic functions, including anti-cancer, -diabetic, -inflammatory, immunomodulatory and anti-oxidant effects $(19,20)$. Due to the rarity of wild $C$. sinensis fruiting bodies, the artificial cultivation of $C$. sinensis has emerged as an attractive substitute for the preparation of health supplements $(21,22)$. Previous studies have indicated that this medicine may also have a protective effect against lung diseases $(23,24)$. In a previous study conducted by the present research group, it was revealed that $C$. sinensis was able to significantly inhibit senescence via the reactive oxygen species and phosphoinositide 3-kinase/AKT/mechanistic target of rapamycin signaling pathways in cigarette smoke extract (CSE)-induced 16 human bronchial epithelial cells (HBEs) (25). Previous reports have suggested that $C$. sinensis may have anti-fibrotic effects $(24,26,27)$. It was therefore hypothesized that $C$. sinensis may inhibit airway remodeling in COPD. To test this hypothesis, the present study investigated the effect of $C$. sinensis on airway remodeling in vivo and explored its underlying mechanisms in COPD.

\section{Materials and methods}

Rat model of COPD and $C$. sinensis treatment. A total of 50 male Wistar rats (body weight, 200 20 g; age, 8-10 weeks) were purchased from the Shandong University Experimental Animal Center (Jinan, China), and the animal experiments were performed in accordance with and approved by the Institutional Animal Care and Use Committee of Shandong University (Jinan, China). The rats were housed in $24 \pm 1^{\circ} \mathrm{C}$ with humidity of $50 \pm 10 \%$, a $12 \mathrm{~h} \mathrm{light/dark} \mathrm{cycle} \mathrm{and} \mathrm{had}$ access to a standard diet and water ad libitum. The rats were randomly divided into five groups as follows: Control group (CON); COPD group (COPD); COPD + low dose of $C$. sinensis group (LOW; $2.5 \mathrm{~g} / \mathrm{kg} /$ day $C$. sinensis); COPD + moderate dosage of $C$. sinensis group (MOD; $5 \mathrm{~g} / \mathrm{kg} / \mathrm{day} C$. sinensis); and COPD + high dose of $C$. sinensis group (HIG; $7.5 \mathrm{~g} / \mathrm{kg} / \mathrm{day}$ C. sinensis) (n=10/group).

The rat model of COPD was established by cigarette smoking and an intratracheal injection of lipopolysaccharide (LPS), according to a previous report (28). Briefly, intratracheal injection of $1 \mathrm{mg} / \mathrm{ml}$ LPS (Sigma-Aldrich; Merck KGaA, Darmstadt, Germany) was conducted on day $1(0.2 \mathrm{ml})$ and 14 $(0.1 \mathrm{ml})$. Except for days 1 and 14, rats were exposed to smoke generated by 8 cigarettes (Hademen ${ }^{\circledR}$ Filter tip cigarette; Jinan Cigarette Factory of China Tobacco Shandong Industrial Co., Ltd., Jinan, China; tar, $10 \mathrm{mg}$; nicotine content, $1.0 \mathrm{mg}$; carbon monoxide, $12 \mathrm{mg}$ ) in a sealed box connected to the smoke source for $30 \mathrm{~min}$, twice daily for the first 2 weeks; then 15 cigarettes per treatment, three times daily for 10 weeks. Artificially cultured $C$. sinensis powder was obtained from Hangzhou Zhongmei Huadong Pharmaceutical Co., Ltd. (Hangzhou, China). C. sinensis powder was dissolved in normal saline $(500 \mathrm{mg} / \mathrm{ml})$ to prepare the turbid liquid suspension, and applied to the LOW, MOD and HIG groups (2.5, 5 or $7.5 \mathrm{~g} / \mathrm{kg} /$ day, respectively) intragastrically following cigarette smoke exposure once a day for 12 weeks. Rats in the CON group were exposed to air and treated with PBS. After 12 weeks, rats were sacrificed with an intraperitoneal injection of pentobarbital sodium (150 mg/kg; Sigma-Aldrich; Merck KGaA).
Bronchoalveolar lavage fluid $(B A L F)$. BAL was performed in the left lung through a tracheal cannula under anesthesia using $1 \mathrm{ml}$ sterile isotonic saline three times in each rat. The BALF was immediately centrifuged at $200 \mathrm{x}$ g for $10 \mathrm{~min}$ at $4^{\circ} \mathrm{C}$. The supernatant was stored at $-80^{\circ} \mathrm{C}$ for cytokine measurements. Total cell counts in BALF were performed using a hemocytometer. Differential cell counts were performed on cytospin preparations with Wright-Giemsa stain. Briefly, the cells were evenly coated on clean glass slides and fixed with absolute methanol after drying at room temperature. The slides were stained with Wright's-Giemsa solution for $10 \mathrm{~min}$ at room temperature, then washed, dried and observed by light microscope (original magnification, x1,000; Olympus Corporation, Tokyo, Japan). At least 200 cells/sample were scored.

ELISA. The levels of interleukin (IL)-8 (cat. no. MBS7606869; MyBioSource, Inc., San Diego, CA, USA), tumor necrosis factor (TNF)- $\alpha$ (cat. no. RTA00; R\&D Systems, Inc., Minneapolis, MN, USA) and TGF- $\beta 1$ (cat. no. MB100B; R\&D Systems, Inc.) were determined using a sandwich ELISA method, according to the manufacturer's protocol.

Histopathological analysis. Tissue samples from the left lung of euthanized rats were fixed with $4 \%$ paraformaldehyde at room temperature for $24 \mathrm{~h}$ and processed for paraffin embedding. Lung paraffin sections were sliced to 5- $\mu$ m-thick sections and then stained with hematoxylin ( $3 \mathrm{~min})$ and eosin (1 min) at room temperature using a staining kit (cat. no. G1120; Beijing Solarbio Science \& Technology Co., Ltd., Beijing, China) under a light microscope (original magnification, x200; Olympus Corporation).

The lung sections were also examined with Masson's trichrome stain to assess the deposition of peribronchial collagen. Following dewaxing and hydration with xylene and a gradient concentration of ethanol (100, 95, 80 and 70\%). The slides were stained with Weigert iron hematoxylin for $8 \mathrm{~min}$ and then differentiated with $1 \%$ hydrochloric acid alcohol. Subsequently, slides were stained with Ponceau fuchsin for $8 \mathrm{~min}$. Following staining with phosphomolybdic acid solution for $\sim 5 \mathrm{~min}$, the slides were stained with aniline blue for $5 \mathrm{~min}$, differentiated in $1 \%$ acetic acid for $1 \mathrm{~min}$, dehydrated in an ascending series of ethanol (95 and 100\%), washed in xylene and sealed with neutral gum. All steps were conducted at room temperature. Masson's trichrome staining was used to differentiate collagen from other fibers, staining nuclei in black, cytoplasm and muscles in red and collagen in blue. The sections were visualized using a light microscope at a magnification of $\mathrm{x} 200$.

Additionally, three random microscope fields in which the bronchiole diameters were $<100 \mu \mathrm{m}$ (shortest path/lumen diameter, cope fields in which the brox 200 were observed to determine the changes of thickness and area of the tube wall. The wall area/total bronchiole area (MA\%) and the wall thickness/bronchiole diameter (MT\%) were then calculated.

In the present study, it was found that the moderate (5 g/ kg/day) and high (7.5 g/ $\mathrm{kg} /$ day) dose of C. sinensis group had a marked inhibitory effect on airway remodeling parameters compared with the low $(2.5 \mathrm{~g} / \mathrm{kg} /$ day $)$ dose group, but there was no significance between 5 and $7.5 \mathrm{~g} / \mathrm{kg} /$ day 
treatments. Therefore, the $5 \mathrm{~g} / \mathrm{kg} / \mathrm{day}$ dose of $C$. sinensis was selected for pathological evaluation in following experiments.

Immunohistochemistry. Immunohistochemistry was performed by a two-step immunoperoxidase protocol. Lung tissue was fixed at room temperature in $4 \%$ paraformaldehyde for $24 \mathrm{~h}$ and embedded in paraffin an sliced into a 4- $\mu$ m-thick sections. Slides were deparaffinized, rehydrated with xylene and ethanol of gradient concentration $(100,95,80$ and $70 \%)$ and antigen retrieval was performed by microwave $\left(95^{\circ} \mathrm{C}, 15-20 \mathrm{~min}\right)$. Endogenous peroxidases were blocked by soaking slides in $3 \% \mathrm{H}_{2} \mathrm{O}_{2}$ for $30 \mathrm{~min}$ at room temperature. Subsequently, the slides were incubated with anti- $\alpha$-SMA (1:200; cat. no. sc-53142), anti-collagen I (1:100; cat. no. sc-59772; both Santa Cruz Biotechnology, Inc., Dallas, TX, USA), anti-TGF- $\beta 1$ (1:100; cat. no. ab92486), anti-TGF- $\beta$ receptor (T $\beta$ R) I (1:100; cat. no. ab31013) and anti-T $\beta$ R II (1:100; cat. no. ab186838; all Abcam, Cambridge, MA, USA) antibodies overnight at $4^{\circ} \mathrm{C}$ in a humidified chamber. Following this, the sections were incubated with the secondary horseradish peroxidase-conjugated goat anti-rabbit (cat. no. ZB-2301) and goat anti-mouse (cat. no. ZB-2305) antibodies (both 1:500; OriGene Technologies, Inc., Beijing, China) for $1 \mathrm{~h}$ at room temperature. Sections were stained with diaminobenzidine for 2-5 min and counterstained with $10 \%$ hematoxylin for $3 \mathrm{~min}$ at room temperature. Stained areas of the sections were visualized using a light microscope at magnification of x200. Positive areas were quantified by densitometry using Image-Pro Plus software (version 6.0; Media Cybernetics, Inc., Rockville, MD, USA).

Western blotting. Total proteins in right lung tissue samples from each group were extracted prior to western blotting. Lung tissue was mixed with RIPA lysate buffer (P0013K; Beyotime Institute of Biotechnology, Haimen, China) with a ratio of $100 \mathrm{mg} / \mathrm{ml}$. The mixture was centrifuged $(12,000 \mathrm{x} \mathrm{g})$ at $4^{\circ} \mathrm{C}$ for $5 \mathrm{~min}$ to collect the supernatant. The total protein was quantitated using a Pierce BCA Protein Assay Kit. The protein $(20 \mu \mathrm{g} / \mathrm{lane})$ was loaded and separated using $10 \%$ SDS-PAGE, and subsequently transferred onto polyvinylidene difluoride (PVDF) membranes (Immobilon; EMD Millipore, Billerica, MA, USA) at $4^{\circ} \mathrm{C}$. The PVDF membranes were blocked with $5 \%$ skim milk in Tris-buffered saline with Tween 20 (TBST) for $60 \mathrm{~min}$ at room temperature. The membranes were incubated with the following antibodies: Anti-TGF- $\beta 1$ (1:500), anti-T $\beta$ R I (1:500), anti-T $\beta$ R II (1:500), anti-collagen I $(1: 1,000)$ anti- $\alpha$-SMA $(1: 1,000)$, anti-phosphorylated (p)-Smad2 (1:1,000; cat. no. 3104, Cell Signaling Technology, Inc., Danvers, MA, USA), anti-p-Smad3 (1:1,000; cat. no. 9520, Cell Signaling Technology, Inc.) anti-Smad7 (1:1,000; cat. no. sc-365846) and GAPDH (1:1,000; cat. no. sc-47724; both Santa Cruz Biotechnology, Inc.) overnight at $4^{\circ} \mathrm{C}$. The membrane was washed three times for 5 min each with $1 \mathrm{X}$ TBS containing 0.15 Tween-20 followed by incubation with secondary horseradish peroxidase-conjugated goat anti-rabbit and anti-mouse antibodies (both $1: 5,000$ ) at $37^{\circ} \mathrm{C}$ for $1 \mathrm{~h}$. The immunoreactive bands were visualized by a enhanced chemiluminescence kit (cat. no. K820-500; BioVision, Inc. Milpitas, CA, USA). GAPDH was used for normalization. The quantification of protein expression was analyzed by densitometry using Image J software (version 1.46; National Institutes of Health, Bethesda, MD, USA).

In the present study, it was found that $C$. sinensis at a dose of $5 \mathrm{~g} / \mathrm{kg} /$ day efficiently decreased the protein and mRNA expression levels of TGF- $\beta 1$, T $\beta \mathrm{R}$ I and T $\beta \mathrm{R}$ II, but there was no significant difference between 5 and $7.5 \mathrm{~g} / \mathrm{kg} /$ day treatments. Therefore, the optimal dose was $5 \mathrm{~g} / \mathrm{kg} /$ day of $C$. sinensis, which was selected for following experiments.

Reverse transcription-quantitative polymerase chain reaction $(R T-q P C R)$. Total RNA was extracted from the right lung tissue of rats using TRIzol reagent (Takara Bio, Inc., Otsu, Japan) according to the manufacturer's protocol. Total RNA was extracted from the right lung tissue of rats using TRIzol reagent (Takara Bio, Inc., Otsu, Japan) according to the manufacturer's protocol. A total of $1 \mu \mathrm{g}$ total RNA was used for reverse transcription with PrimeScript RT Master Mix (TaKaRa, Bio, Inc) according to the manufacturer's protocol. qPCR was performed by using the SYBR ${ }^{\circledR}$ Premix Ex Taq ${ }^{\mathrm{TM}}$ II (Takara Bio, Inc.) according to the manufacturer's protocol on a LightCycler 480 System (Roche Diagnostics, Basel, Switzerland). The qPCR reaction mixture consisted of $2 \mu \mathrm{l}$ cDNA, $10 \mu \mathrm{l}$ SYBR Premix Ex Taq II (2X), $0.8 \mu \mathrm{l}$ of $10 \mathrm{uM}$ forward primer, $0.8 \mu \mathrm{l}$ of $10 \mathrm{uM}$ reverse primer, and $6.4 \mu \mathrm{l}$ double distilled $\mathrm{H}_{2} \mathrm{O}$ to a final volume $20 \mu \mathrm{l}$. The thermocycling conditions were as follows: $95^{\circ} \mathrm{C}$ for $30 \mathrm{sec}$ (initial denaturation), followed by 40 cycles of $95^{\circ} \mathrm{C}$ for $5 \mathrm{sec}$ (denaturation) and $60^{\circ} \mathrm{C}$ for $30 \mathrm{sec}$ (annealing). Next, a melting curve was performed at $95^{\circ} \mathrm{C}$ for $5 \mathrm{sec}, 60^{\circ} \mathrm{C}$ for $1 \mathrm{~min}$ and then continuously at $95^{\circ} \mathrm{C}$, followed by $50^{\circ} \mathrm{C}$ for $30 \mathrm{sec}$ (cooling). Relative quantification of mRNA was calculated using the $2^{-\Delta \Delta \mathrm{Cq}}$ method (29). The sequences of primers used for RT-qPCR in the present study are demonstrated in Table I. GAPDH gene was used as an internal control.

Statistical analyses. All data are presented as the mean \pm standard error of the mean. All experiments in the present study were repeated at least three times. One-way analysis of variance followed by Newman-Keuls post hoc tests were used to compare measurements of individual groups. The statistical analysis was conducted using SPSS software (version 19.0; IBM Corp, Armonk, NY, USA). P<0.05 was considered to indicate a statistically significant difference.

\section{Results}

Effect of $C$. sinensis on histopathology in rats with COPD. To detect the airway structural changes in rats with COPD, the slides from each group were stained with H\&E. As demonstrated in Fig. 1A, airway structural changes, including airway wall thickening, numerous inflammatory cell infiltration, subepithelial fibrosis, increased smooth muscle mass and epithelial metaplasia, were observed in the COPD group. However, $C$. sinensis treatment markedly ameliorated the aforementioned changes. In addition, Masson's trichrome staining was used to reveal the deposition of collagen and proliferation of smooth muscle hypertrophy in airway areas of the COPD group, while these changes were effectively decreased in rats treated with $C$. sinensis (Fig. 1B). Additionally, a significantly larger bronchiole tube area, thicker tube wall surrounded by proliferative connective 
Table I. Primer sequences used for reverse transcription-quantitative polymerase chain reaction.

Primer sequence

\begin{tabular}{lll}
\cline { 2 - 3 } Target gene & \multicolumn{1}{c}{ Forward (5'-3') } & \multicolumn{1}{c}{ Reverse (5'-3') } \\
\hline Transforming growth factor- $\beta 1$ & CAACAATTCCTGGCGTTACCTTGG & GAAAGCCCTGTATTCCGTCTCCTT \\
$\alpha$-smooth muscle actin & CCACCGCAAATGCTTCTAAGT & GGCAGGAATGATTTGGAAAGG \\
Collagen I & TGCCGTGACCTCAAGATGTG & CACAAGCGTGCTGTAGGTGA \\
T $\beta$ R I & GAGGTGTCAGACTGATTTTCAGGAG & ATGTCACAAAGGAAATCATAAAGC \\
T $\beta$ R II & GGCTCTGGTACTCTGGGAAA & AATGGGGGCTCGTAATCCT \\
GAPDH & GTGGCAAAGTGGAGATTGTT & CTCGCTCCTGGAAGATGG
\end{tabular}

$\mathrm{T} \beta \mathrm{R}$, transforming growth factor- $\beta$ receptor.
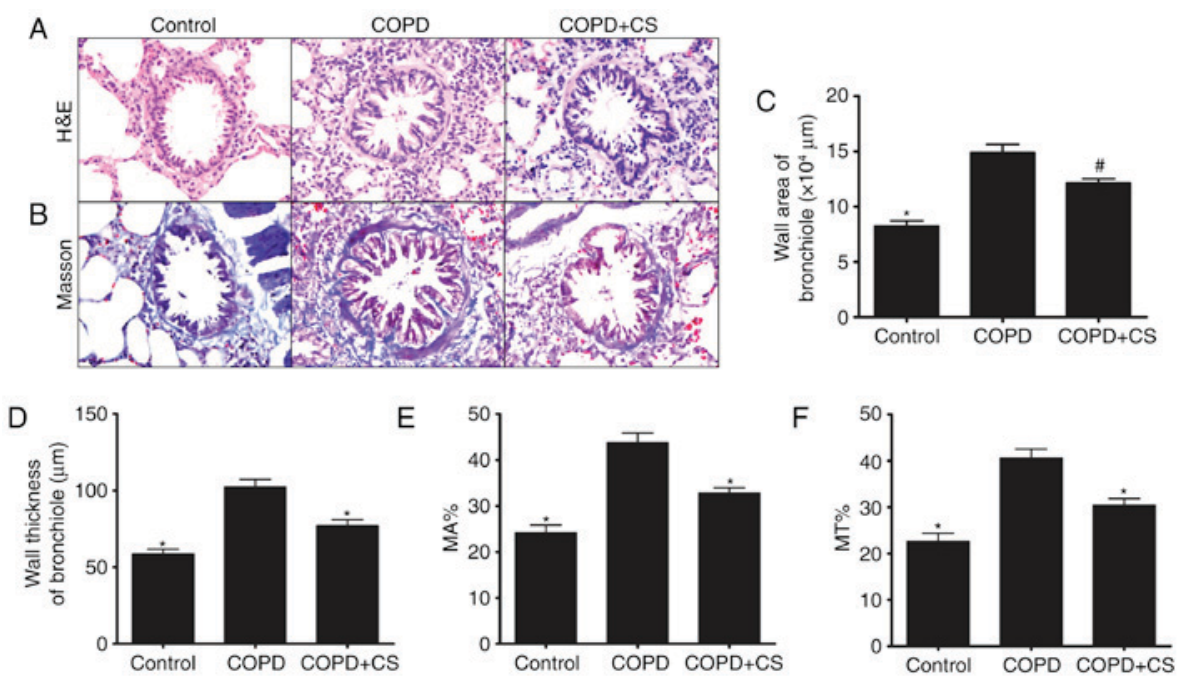

Figure 1. Effect of CS on histopathology in rats with COPD. (A) H\&E and (B) Masson's trichrome staining of samples of the left lung of rats with COPD (magnification, x200). Rats with COPD demonstrated a significantly (C) larger bronchiole tube area, (D) thicker tube wall, (E) increased MA\% and (F) MT\% compared with that observed in rats in the control group, which could be effectively improved by CS treatment. ${ }^{~} \mathrm{P}<0.05$ and ${ }^{~} \mathrm{P}<0.01$ vs. COPD group. CS, Cordyceps sinensis; COPD, chronic obstructive pulmonary disease; H\&E, hematoxylin and eosin; MA\%, wall area/total bronchiole area; MT\%, wall thickness/bronchiole diameter.

tissue and increased MA\% and MT\% were detected in the COPD compared with that observed in the control group $(\mathrm{P}<0.01)$. These characteristics were significantly improved by $C$. sinensis treatment $(\mathrm{P}<0.05$; Fig. $1 \mathrm{C}-\mathrm{F})$.

C. sinensis attenuates lung inflammatory responses in a rat model of COPD. As inflammation serves an important role in the development of airway remodeling in COPD, the effect of $C$. sinensis treatment on lung inflammation was evaluated. BALF cell counts were performed to examine the effect of C. sinensis on the inflammatory response induced by cigarette smoke. Smoking treatment induced extensive infiltration of inflammatory cells, as demonstrated by the significant increase in the numbers of total cells, macrophages, neutrophils and lymphocytes in the COPD group compared with the numbers in the CON group $(\mathrm{P}<0.01)$. C . sinensis significantly reversed all types of cell accumulation in BALF of the COPD rats $(\mathrm{P}<0.05$; Fig. 2A-D). In addition, the inflammatory cytokines, including TNF- $\alpha$, IL- 8 and TGF- $\beta 1$, in BALF were significantly increased in the rats with COPD compared with the levels observed in the CON group (P<0.01; Fig. 2E-G), and the production of TNF- $\alpha$, IL- 8 and TGF- $\beta 1$ were significantly reduced in rats treated with $C$. sinensis at all treatment doses ( $\mathrm{P}<0.01$; Fig. 2E-G).

C. sinensis inhibits the expression of collagen I and $\alpha-S M A$ in rats with $C O P D$. To detect whether $C$. sinensis could inhibit airway remodeling, the effect of $C$. sinensis on the expression of collagen I and $\alpha$-SMA in rats with COPD was examined by immunohistochemistry, western blotting and RT-qPCR. The present study revealed that the protein and mRNA expression levels of collagen I and $\alpha$-SMA were significantly elevated in rats with COPD compared with the levels observed in the CON group $(\mathrm{P}<0.05$; Fig. $3 \mathrm{~A}-\mathrm{C})$. However, the collagen I and $\alpha$-SMA protein and mRNA expression levels were significantly decreased in rats treated with $C$. sinensis $(\mathrm{P}<0.05$; Fig. 3A-C).

$C$. sinensis reduces the expression of TGF- $\beta 1$ and its receptors in the airway. A role for TGF- $\beta 1$ has been proposed in 


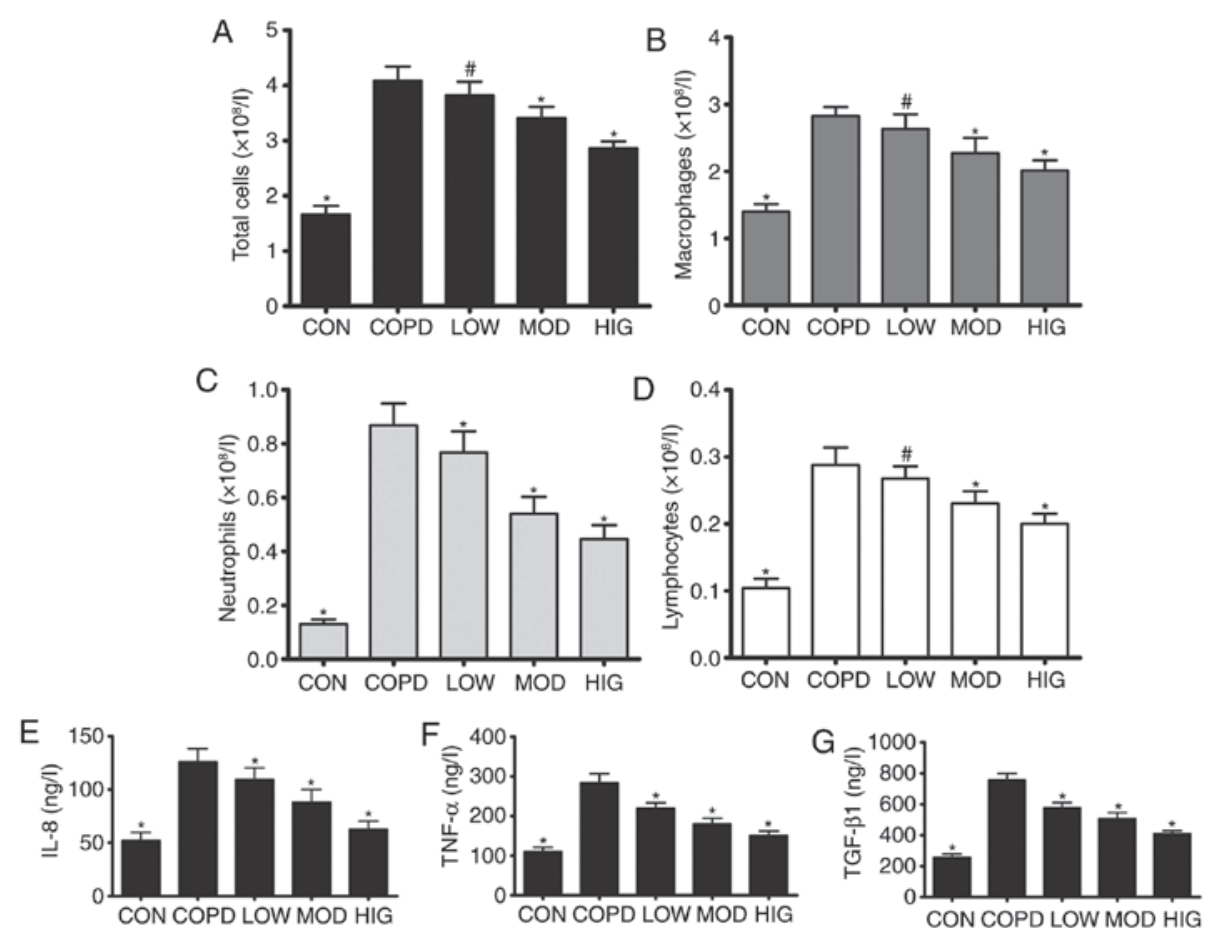

Figure 2. C. sinensis reduces lung inflammation in rats with COPD. BALF was collected to quantify (A) total cells, (B) macrophages, (C) neutrophils and (D) lymphocytes. ELISA was used to determine the production of (E) IL-8, (F) TNF- $\alpha$ and (G) TGF- $\beta 1$ in BALF. Data are expressed as mean + standard error of the mean. Each result represents at least three independent experiments. ${ }^{~} \mathrm{P}<0.05$ and ${ }^{~} \mathrm{P}<0.01$ vs. COPD group. C. sinensis, Cordyceps sinensis; COPD, chronic obstructive pulmonary disease; BALF, bronchoalveolar lavage fluid; TNF- $\alpha$, tumor necrosis factor- $\alpha$; IL- 8 , interleukin- 8 ; TGF- $\beta 1$, transforming growth factor- $\beta 1$; CON, control group; LOW, COPD + low dose of $C$. sinensis $(2.5 \mathrm{~g} / \mathrm{kg} / \mathrm{day}) ; \mathrm{MOD}, \mathrm{COPD}+$ moderate dose of $C$. sinensis (5 g/kg/day); HIG, COPD + high dose of C. sinensis ( $7.5 \mathrm{~g} / \mathrm{kg} / \mathrm{day})$.

A
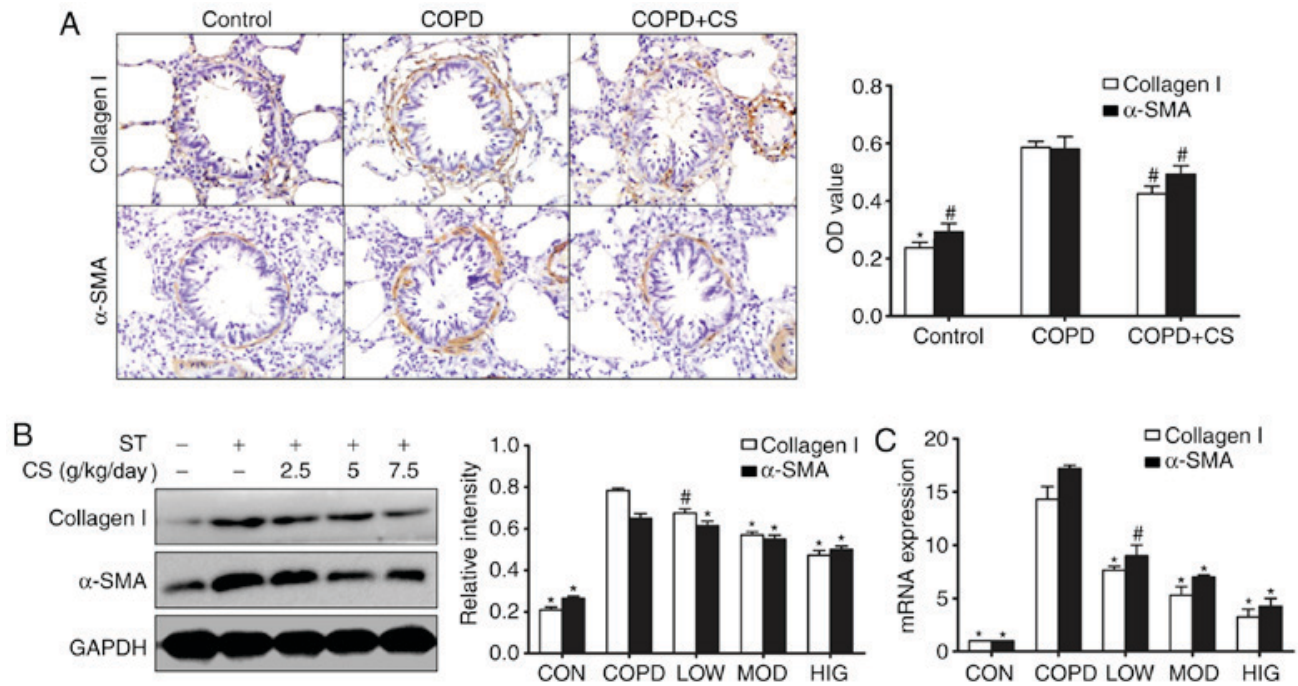

Figure 3. CS reduces the markers of airway remodeling in rats with COPD. (A) The expression of $\alpha$-SMA and collagen I were detected by immunohistochemistry (magnification, x200). $\alpha$-SMA and collagen I immunoreactive cells were stained brown by immunohistochemical staining. (B) The production of $\alpha$-SMA and collagen I were analyzed by western blotting. (C) The mRNA expression levels of collagen I and $\alpha$-SMA were detected by reverse transcription-quantitative polymerase chain reaction. Data are expressed as mean + standard error of the mean. Each result represents at least three independent experiments. ${ }^{*} \mathrm{P}<0.05$ and " $\mathrm{P}<0.01$ vs. COPD group. CS, Cordyceps sinensis; COPD, chronic obstructive pulmonary disease; ST, smoking treatment; $\alpha$-SMA, $\alpha$-smooth muscle actin; CON, control group; LOW, COPD + low dose of CS (2.5 g/kg/day); MOD, COPD + moderate dose of CS (5 g/kg/day); HIG, COPD + high dose of CS (7.5 g/kg/day); OD, optical density.

airway remodeling of COPD $(6,9,10)$. To explore the mechanisms by which $C$. sinensis inhibits airway remodeling, the expression levels of TGF- $\beta 1$, T $\beta$ R I and T $\beta R$ II were assessed by immunohistochemistry, western blotting and RT-qPCR. As demonstrated in Fig. 4, the protein and mRNA expression levels of TGF- $\beta 1$ were significantly increased in rats with COPD compared with the levels observed in the CON group $(\mathrm{P}<0.01)$. Meanwhile, the protein expression levels of T $\beta \mathrm{R} I$ and $T \beta R$ II were also significantly increased in the COPD group compared with the levels observed in the $\mathrm{CON}$ group $(\mathrm{P}<0.01)$. 
A
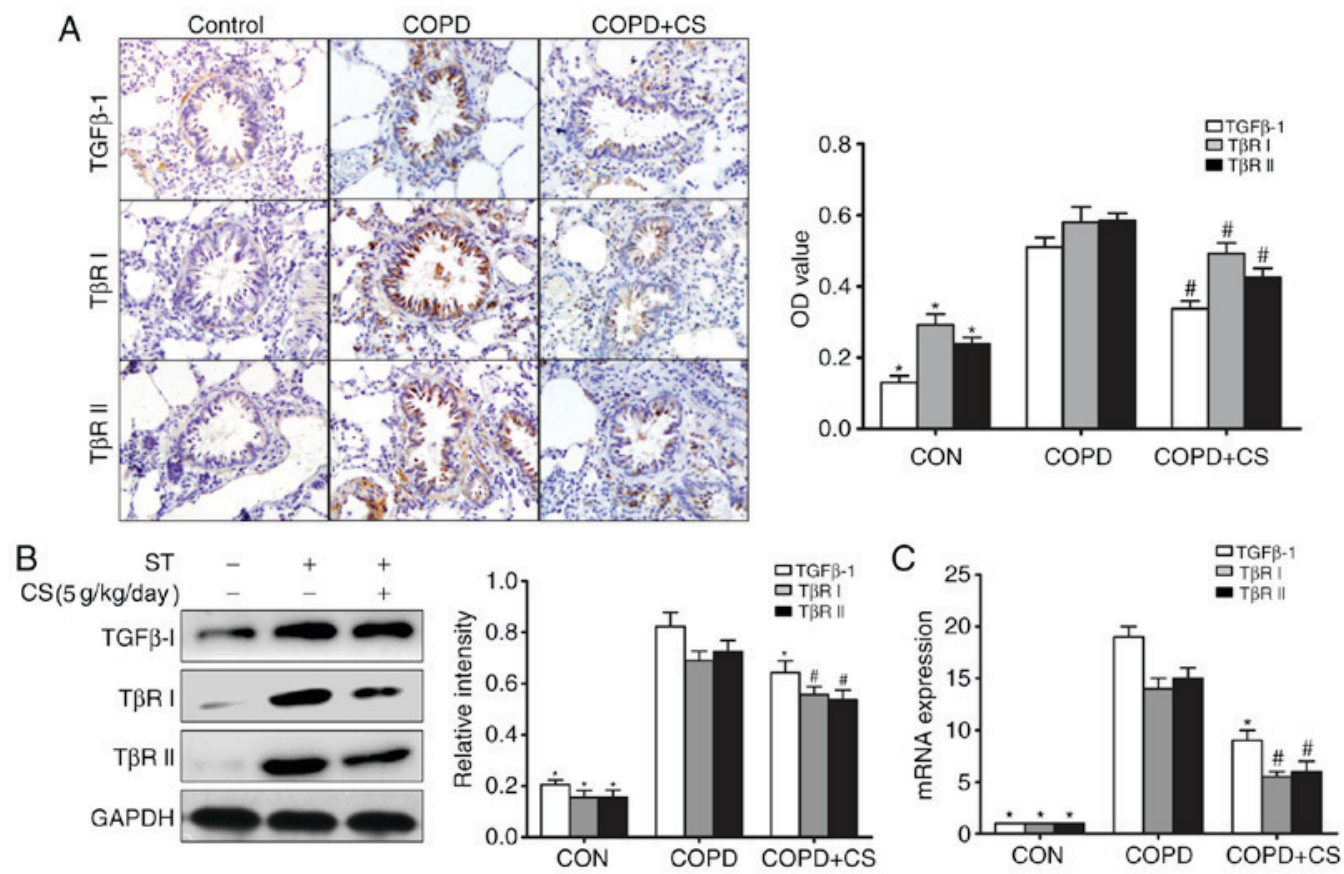

Figure 4. CS reduces expression of TGF- $\beta 1$ and its receptors in the airways. (A) Immunohistochemistry of TGF- $\beta 1$, T $\beta R$ I and T $\beta R$ II. TGF- $\beta 1$, T $\beta R$ I and T $\beta R$ II immunoreactive cells were stained brown by immunohistochemical staining. (B) Western blot analysis of TGF- $\beta 1$, T $\beta R$ I and T $\beta R$ II protein expression levels. (C) The mRNA expression levels of TGF- $\beta 1, T \beta R$ I and T $\beta R$ II were analyzed by reverse transcription-quantitative polymerase chain reaction. Data are expressed as mean + standard error of the mean. Each result represents at least three independent experiments. ${ }^{*} \mathrm{P}<0.05$ and ${ }^{*} \mathrm{P}<0.01$ vs. COPD group. CS, Cordyceps sinensis; COPD, chronic obstructive pulmonary disease; ST, smoking treatment; TGF- $\beta 1$, transforming growth factor- $\beta 1$; T $\beta$ R, TGF- $\beta$ receptor; OD, optical density.
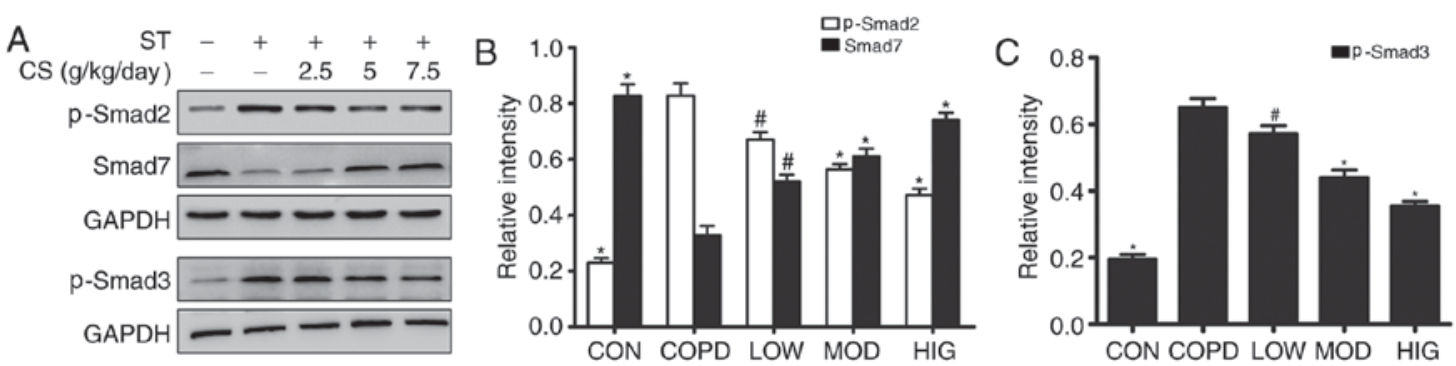

Figure 5. Effect of CS on the TGF- $\beta 1 /$ Smad signaling pathway in rats with COPD. (A) CS treatment induced the phosphorylation of Smad2 and Smad3 and upregulation of Smad7 in rats with COPD, according to western blotting. Quantitation of (B) p-Smad2 and Smad7, and (C) p-Smad3. Data are expressed as mean + standard error of the mean. ${ }^{*} \mathrm{P}<0.05$ and ${ }^{*} \mathrm{P}<0.01$ vs. COPD group. CS, Cordyceps sinensis; COPD, chronic obstructive pulmonary disease; $\mathrm{ST}$, smoking treatment; p, phosphorylated; CON, control group; LOW, COPD + low dose of CS (2.5 g/kg/day); MOD, COPD + moderate dose of CS (5 g/kg/day); HIG, COPD + high dose of CS (7.5 g/kg/day).

The administration of $C$. sinensis significantly attenuated TGF- $\beta 1, T \beta R$ I and T $\beta R$ II expression ( $\mathrm{P}<0.05$; Fig. 4A-C).

Effect of C. sinensis on the TGF- $\beta 1 /$ Smad signaling pathway. The TGF- $\beta 1 /$ Smad signaling pathway is crucial in the regulation of the transcription of genes involved in airway remodeling in COPD (13). As demonstrated in the present study, the expression levels of signal proteins of $\mathrm{p}-\mathrm{Smad} 2$ and $\mathrm{p}-\mathrm{Smad} 3$ were significantly upregulated in the COPD group compared with the levels observed in the $\mathrm{CON}$ group $(\mathrm{P}<0.01$; Fig. 5A-C). The expression of Smad7 was significantly decreased in the COPD group compared with the level observed in the CON group $(\mathrm{P}<0.01)$. Administration of $C$. sinensis for 12 weeks significantly decreased the high expression of p-Smad2 and p-Smad3 $(\mathrm{P}<0.05)$, and increased the protein expression level of Smad7 $(\mathrm{P}<0.05)$ in rats with COPD to different degrees (Fig. 5A-C).

\section{Discussion}

C. sinensis has been used in traditional Chinese medicine to treat lung disease for centuries due to its pharmacological and therapeutic effects (30). There has been an increased interest in the anti-fibrotic effect of $C$. sinensis $(24,26,27)$. The present study investigated the inhibitory effect of $C$. sinensis on airway remodeling in rats with COPD. It was demonstrated that $C$. sinensis inhibited the accumulation of inflammatory cells and production of cytokines in BALF of rats with COPD. Meanwhile, $C$. sinensis treatment also reduced the protein and mRNA expression levels of collagen I, $\alpha$-SMA, TGF- $\beta 1$ as well as its receptors. Additionally, the present study revealed that $C$. sinensis regulated the expression of key signal proteins of the TGF- $\beta 1 /$ Smad pathway, which may influence the regulation of airway remodeling. 
Various studies have indicated that inflammation serves an important role in COPD airway remodeling (31-33). Chronic inflammation could initiate the frequent occurrence of injury and repair, which contributes to airway structural changes and airway remodeling. Previous studies have demonstrated that various proinflammatory cytokines and profibrotic growth factors are involved in airway injury and repairing (34-36). C. sinensis has been indicated to have effects on anti-inflammatory and immunomodulatory activities in vitro and in vivo $(37,38) . C$. sinensis may suppress IL-1 $\beta$, TNF- $\alpha$, IL- 6 and IL-8 cytokine production in BALF (39). In the present study, it was observed that the numbers of total cells, macrophages, neutrophils and lymphocytes were significantly increased in BALF of the model rats with COPD, and these numbers could be alleviated by $C$. sinensis treatment. Consistent with the previous observation, it was observed that the production of cytokines, including TNF- $\alpha$, IL- 8 and TGF- $\beta 1$, in rats with COPD were reduced by $C$. sinensis treatment. These findings suggest that $C$. sinensis has anti-inflammatory activities in vivo, as shown by reduced inflammatory cell counts, and decreased expression levels of IL-8, TNF- $\alpha$ and TGF- $\beta 1$ in BALF of rats with COPD. Overall, the present results support that suppression of airway inflammation may contribute to the protective effect of $C$. sinensis in COPD.

TGF- $\beta 1$ is an important profibrotic cytokine, which has been widely implicated in the pathogenesis of airway repair and remodeling $(9,10)$. TGF- $\beta 1$ promotes collagen deposition, airway smooth muscle cell and fibroblast proliferation, and epithelial-to-mesenchymal transition $(10,40)$. TGF- $\beta$ serves multiple biological effects through Smad-dependent and Smad-independent signaling pathways $(13,18)$. Smad signaling is recognized as the most critical signaling pathway of airway remodeling $(10,13)$. Previous research has suggested that specific inhibitor of Smad3 may inhibit TGF- $\beta 1$-induced expression of type I collagen in normal fibroblasts and scleroderma fibroblasts (41). A study by Le et al (42) demonstrated that airway remodeling was alleviated in Smad3-deficient mice, with a decrease in collagen deposition and the smooth muscle layer. Based on these previous studies, it was hypothesized that inhibiting the TGF- $\beta 1 /$ Smad signaling pathway may be a useful therapeutic method against airway remodeling.

In COPD, various factors have been revealed to activate the TGF- $\beta 1 /$ Smad signaling pathway (43-45). Rats exposed to cigarette smoke highly express TGF- $\beta$ and upregulate downstream signature protein $\mathrm{p}-\mathrm{Smad} 2$, accompanied by an increase in collagen deposition (14). In the present study, it was identified that the expression levels of TGF- $\beta 1$, T $\beta$ R I, T $\beta$ R II, $\mathrm{p}-\mathrm{Smad} 2$ and $\mathrm{p}-\mathrm{Smad} 3$ were upregulated in the lungs of rats with COPD. This suggests that cigarette smoke may activate the TGF- $\beta 1 /$ Smad signaling pathway. Previous studies have indicated that $C$. sinensis attenuated liver and renal fibrosis by inhibition of the TGF- $\beta 1 /$ Smad signaling pathway and downregulation of $\alpha$-SMA, collagen and TGF- $\beta 1(26,27)$. In the present study, $C$. sinensis treatment was also demonstrated to decrease TGF- $\beta 1, T \beta R$ I and T $\beta R$ II expression, and suppress phosphorylation of Smad2 and Smad3 while increasing the expression of Smad7 in rats with COPD. Additionally, the biochemical and histological signs of airway remodeling, including collagen I and $\alpha$-SMA in the airway, were also markedly reduced in rats treated with $C$. sinensis.
Therefore, reduction of phosphorylation of Smad2 and Smad3, and upregulation of Smad7 expression may directly lead to an attenuation of airway remodeling in COPD. These results suggest that $C$. sinensis may inhibit the TGF- $\beta 1 / \mathrm{Smad}$ signaling pathway to improve airway remodeling in COPD.

In conclusion, the present study demonstrated that C. sinensis attenuated airway remodeling in rats with COPD by inhibiting airway inflammation and the TGF- $\beta 1 / \mathrm{Smad}$ signaling pathway. These findings suggest $C$. sinensis may be a useful approach for COPD therapy.

\section{Acknowledgements}

The present research was supported by the National Nature Science Foundation of China (grant no. 81270072 for LD), the Natural Science Funding Committee of Shandong province (grant no. ZR2015PH022) and the Key Research Project of Shandong province (grant no. 2016GSF201028).

\section{References}

1. Global Initiative for Chronic Obstructive Lung Disease 2016. Global strategy for the diagnosis, management and prevention of chronic obstructive pulmonary disease. www.goldcopd.org (Updated 2016).

2. Caramori G, Casolari P, Giuffrè S, Barczyk A, Adcock I and Papi A: COPD pathology in the small airways. Panminerva Med 53: 51-70, 2011.

3. Decramer M, Janssens W and Miravitlles M: Chronic obstructive pulmonary disease. Lancet 379: 1341-1351, 2012.

4. Hirota $\mathrm{N}$ and Martin JG: Mechanisms of airway remodeling. Chest 144: 1026-1032, 2013.

5. Aoshiba K and Nagai A: Differences in airway remodeling between asthma and chronic obstructive pulmonary disease. Clin Rev Allergy Immunol 27: 35-43, 2004.

6. Barnes PJ: The cytokine network in chronic obstructive pulmonary disease. Am J Respir Cell Mol Biol 41: 631-638, 2009.

7. Hogg JC and Timens W: The pathology of chronic obstructive pulmonary disease. Annu Rev Pathol 4: 435-459, 2009.

8. Hogg JC, Chu F, Utokaparch S, Woods R, Elliott WM, Buzatu L, Cherniack RM, Rogers RM, Sciurba FC, Coxson HO and Paré PD: The nature of small-airway obstruction in chronic obstructive pulmonary disease. N Engl J Med 350: 2645-2653, 2004.

9. Churg A, Tai H, Coulthard T, Wang R and Wright JL: Cigarette smoke drives small airway remodeling by induction of growth factors in the airway wall. Am J Respir Crit Care Med 174: 1327-1334, 2006

10. Bartram U and Speer CP: The role of transforming growth factor beta in lung development and disease. Chest 125: 754-765, 2004.

11. de Boer WI, van Schadewijk A, Sont JK, Sharma HS, Stolk J, Hiemstra PS and van Krieken JH: Transforming growth factor betal and recruitment of macrophages and mast cells in airways in chronic obstructive pulmonary disease. Am J Respir Crit Care Med 158: 1951-1957, 1998.

12. Takizawa H, Tanaka M, Takami K, Ohtoshi T, Ito K, Satoh M, Okada Y, Yamasawa F, Nakahara K and Umeda A: Increased expression of transforming growth factor-betal in small airway epithelium from tobacco smokers and patients with chronic obstructive pulmonary disease (COPD). Am J Respir Crit Care Med 163: 1476-1483, 2001.

13. Yang YC, Zhang N, Crombruggen K, Hu GH, Hong SL and Bachert C: Transforming growth factor-betal in inflammatory airway disease: A key for understanding inflammation and remodeling. Allergy 67: 1193-1202, 2012.

14. Chung A, Tai H, Coulthard T, Wang R and Wright JL: Cigarette smoke drives small airway remodeling by induction of growth factors in the airway wall. Am J Respir Crit Care Med 174: 1327-1334, 2006.

15. Qu ZH, Yang ZC, Chen L, Lv ZD, Yi MJ and Ran N: Inhibition airway remodeling and transforming growth factor- $\beta 1 / \mathrm{Smad}$ signaling pathway by astragalus extract in asthmatic mice. Int $\mathrm{J}$ Mol Med 29: 564-568, 2012 . 
16. Gao GX, Li QM and Shen HH: Effect of Astragali-Cordyceps Mixtura on TGF-beta/Smad signal pathway in the lung of asthma airway remodeling. J Ethnopharmacol 13: 68-74, 2009.

17. Nakao A, Afrakhte M, Morén A, Nakayama T, Christian JL, Heuchel R, Itoh S, Kawabata M, Heldin NE, Heldin CH and ten Dijke P: Identification of Smad7, a TGFbeta-inducible antagonist of TGF-beta signalling. Nature 389: 631-635, 1997.

18. Weiss A and Attisano L: The TGFbeta superfamily signaling pathway. Wiley Interdiscip Rev Dev Biol 2: 47-63, 2013.

19. Wu Y, Sun H, Qin F, Pan Y and Sun C: Effect of various extracts and a polysaccharide from the edible mycelia of Cordycepssinensis on cellular and humoral immune response against ovalbumin in mice. Phytother Res 20: 646-652, 2006.

20. Zou Y, Liu Y, Ruan M, Feng X, Wang J, Chu Z and Zhang Z: Cordyceps sinensis oral liquid prolongs the lifespan of the fruit fly, Drosophila melanogaster, by inhibiting oxidative stress. Int J Mol Med 36: 939-946, 2015.

21. Zhou X, Gong Z, Su Y, Lin J and Tang K: Cordyceps fungi: Natural products, pharmacological functions and developmental products. J Pharm Pharmacol 61: 279-291, 2009.

22. Das SK, Masuda M, Sakurai A and Sakakibara M: Medicinal uses of the mushroom Cordyceps militaris: Current state and prospects. Fitoterapia 81: 961-968, 2010.

23. An X, Zhang AL, May BH, Lin L, Xu Y and Xue CC: Oral Chinese herbal medicine for improvement of quality of life in patients with stable chronic obstructive pulmonary disease: A systematic review. J Altern Complement Med 18: 731-743, 2012.

24. Huang TT, Lai HC, Ko YF, Ojcius DM, Lan YW, Martel J, Young JD and Chong KY: Hirsutella sinensis mycelium attenuates bleomycin-induced pulmonary inflammation and fibrosis in vivo. Sci Rep 5: 15282, 2015.

25. Liu A, Wu J, Li A, Bi W, Liu T, Cao L, Liu Y and Dong L: The inhibitory mechanism of Cordyceps sinensis on cigarette smoke extract-induced senescence in human bronchial epithelial cells. Int J Chron Obstruct Pulmon Dis 11: 1721-1731, 2016.

26. Peng J, Li X, Feng Q, Chen L, Xu L and Hu Y: Anti-fibrotic effect of Cordyceps sinensis polysaccharide: Inhibiting HSC activation, TGF- $\beta 1 /$ Smad signalling, MMPs and TIMPs. Exp Biol Med 238: 668-677, 2013

27. Pan MM, Zhang MH, Ni HF, Chen JF, Xu M, Phillips AO and Liu BC: Inhibition of TGF- $\beta 1 /$ Smad signal pathway is involved in the effect of Cordyceps sinensis against renal fibrosis in 5/6 nephrectomy rats. Food Chem Toxicol 58, 487-494, 2013.

28. Qi Y, Shang JY, Ma LJ, Sun BB, Hu XG, Liu B and Zhang GJ: Inhibition of AMPK expression in skeletal muscle by systemic inflammation in COPD rats. Respir Res 15: 156, 2014

29. Livak KJ and Schmittgen TD: Analysis of relative gene expression data using real-time quantitative PCR and the 2(-Delta Delta C(T)) method. Methods 25: 402-408, 2001

30. Bensky D, Clavey S and Stöger E; Chinese Herbal Medicine: Materia Medica, Eastland Press, Seattle, Wash, USA, 2004.

31. Caramori G, Kirkham P, Barczyk A, Di Stefano A and Adcock I: Molecular pathogenesis of cigarette smoking-induced stable COPD. Ann N Y Acad Sci 1340: 55-64, 2015.
32. Durham AL, Caramori G, Chung KF and Adcock IM: Targeted anti-inflammatory therapeutics in asthma and chronic obstructive lung disease. Transl Res 167: 192-203, 2016

33. Barnes PJ, Shapiro SD and Pauwels RA: Chronic obstructive pulmonary disease: Molecular and cellular mechanisms. Eur Respir J 22: 672-688, 2003.

34. Ganesan S and Sajjan US: Repair and remodeling of airway epithelium after injury in chronic obstructive pulmonary disease. Curr Respir Care Rep 2, 2013.

35. Camara J and Jarai G: Epithelial-mesenchymal transition in primary human bronchial epithelial cells is Smad-dependent and enhanced by fibronectin and TNF-alpha. Fibrogenesis Tissue Repair 3: 2, 2010.

36. Doerner AM and Zuraw BL: TGF-betal induced epithelial to mesenchymal transition (EMT) in human bronchial epithelial cells is enhanced by IL-1beta but not abrogated by corticosteroids. Respir Res 10: 100, 2009.

37. Huang TT, Chong KY, Ojcius DM, Wu YH, Ko YF, Wu CY, Martel J, Lu CC, Lai HC and Young JD: Hirsutella sinensis mycelium suppresses interleukin- $1 \beta$ and interleukin-18 secretion by inhibiting bothcanonical and non-canonical inflammasomes. Sci Rep 3: 1374, 2013.

38. Park SY, Jung SJ, Ha KC, Sin HS, Jang SH, Chae HJ and Chae SW: Anti-inflammatory effects of Cordyceps mycelium (Paecilomyces hepiali, CBG-CS-2) in Raw264.7 murine macrophages. Orient Pharm Exp Med 15: 7-12, 2015.

39. Kuo YC, Tsai WJ, Wang JY, Chang SC, Lin CY and Shiao MS: Regulation of bronchoalveolar lavage fluids cell function by the immunomodulatory agents from Cordycepssinensis. Life Sci 68: 1067-1082, 2001

40. Leask A and Abraham DJ: TGF-beta signaling and the fibrutic response. FASEB J 18: 816-827, 2004.

41. Jinnin M, Ihn H and Tamaki K: Characterization of SIS3, a novel specific inhibitor of smad 3 and its effect on transforming growth factor- $\beta 1$-induced extracellular matrix expression. Mol Pharmacol 69: 597-607, 2006.

42. Le AV, Cho JY, Miller M, McElwain S, Golgotiu K and Broide DH: Inhibition of allergen-induced airway remodeling in Smad 3-deficient mice. J Immunol 178: 7310-7316, 2007.

43. Guan S, Liu Q, Han F, Gu W, Song L, Zhang Y, Guo X and Xu W: Ginsenoside Rg1 ameliorates cigarette smoke-induced airway fibrosis by suppressing the TGF- $\beta 1 /$ Smad pathway in vivo and in vitro. Biomed Res Int 2017: 6510198, 2017.

44. Liu X, Hao B, Ma A, He J, Liu X and Chen J: The expression of NOX4 in smooth muscles of small airway correlates with the disease severity of COPD. Biomed Res Int 2016: 2891810, 2016.

45. Aschner $Y$ and Downey GP: Transforming growth factor- $\beta$ : Master regulator of the respiratory system in health and disease. Am J Respir Cell Mol Biol 54: 647-655, 2016.

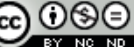

This work is licensed under a Creative Commons Attribution-NonCommercial-NoDerivatives 4.0 International (CC BY-NC-ND 4.0) License. 